УДК 517.9

\author{
А.Г. Андреев ${ }^{1}$, В.С. Ермаков ${ }^{1}$, А.В. Субботин ${ }^{1}$, \\ Д.И. Шевцов ${ }^{1,2}$, М.К. Цибиногина, ${ }^{1,2}$, А.М. Ханов ${ }^{2}$, \\ М.К. Осипчук, ${ }^{1,}$, И.А. Мальцев ${ }^{1,2}$ \\ 1 ОАО «Пермская научно-производственная \\ приборостроительная компания», Пермь, Россия \\ ${ }^{2}$ Пермский национальный исследовательский \\ политехнический университет, Пермь, Россия

\section{МАТЕМАТИЧЕСКОЕ МОДЕЛИРОВАНИЕ ВОЛОКОННЫХ СВЕТОВОДОВ ТИПА «ПАНДА»}

\begin{abstract}
Предложено математическое моделирование (ММ) анизотропных волоконно-оптических световодов (ВС) типа «Панда» с сохранением линейной поляризации, имеющих оптимальную конструкцию с точки зрения максимального двулучепреломления, получаемых методом химического парофразного осаждения (MCVD) с целью повышения производительности технологического процесса изготовления световодов и применения в волоконно-оптическом контуре гироскопа. ММ включает математическое описание физико-химических процессов MCVD-метода и определение поляризационной анизотропии в ВС.
\end{abstract}

Ключевые слова: анизотропные волокна, световоды типа "Панда", MCVD, конструкция оптических волокон, поляризационная анизотропия.

\author{
A.G. Andreev ${ }^{1}$, V.S. Ermakov ${ }^{1}$, A.V. Subbotin ${ }^{1}$, \\ D.I. Shevtsov ${ }^{1,2}$, M.K. Tsibinogina ${ }^{1,2}$, \\ A.M. Khanov', M.K. Osipchuk ${ }^{1,2}$, I.A. Mal'tsev ${ }^{1,2}$ \\ ${ }^{1}$ Perm Scientific-Industrial Instrument Making Company, \\ Perm, Russian Federation \\ ${ }^{2}$ Perm National Research Polytechnic University, Perm, Russian Federation
}

\title{
MATHEMATICAL MODELING OF PANDA TYPE FIBER WAVEGUIDES
}

A mathematical modeling of the anisotropic fiber optic waveguides of the Panda type with the maintaining of linear polarization, having an optimal design from the point of view of maximum birefringence obtained by the chemical vapor deposition (MCVD) method with the aim of increasing the productivity of the manufacturing process of optical fibers and the application in the fiber optic contour of the gyroscope. Modeling includes a mathematical description of the physicochemical processes of the MCVD method and the determination of the polarization anisotropy in the optical fibers. sotropy.

Key words: anisotropic fibers, Panda type optical fibers, MCVD, optical fiber design, polarization ani- 


\section{Введение}

Технология изготовления анизотропных одномодовых волоконных световодов (АОВС) типа «Панда» с сохранением линейной поляризации излучения постоянно совершенствуется. Однако основной способ их изготовления модифицированным методом химического парофазного осаждения (MCVD) не оптимизирован.

В связи с этим в настоящей работе представлено аналитическое описание физико-химических процессов MCVD-метода изготовления AОВС с целью повышения эксплуатационных характеристик изготавливаемого на основе таких АОВС контура гироскопа.

\section{1. Методики эксперимента и исследований}

В ходе исследования была составлена общая схема моделирования (рисунок), которая включает входные технологические параметры MCVD (концентрацию исходных веществ, их расходы, температуру нагрева опорной трубки, скорость перемещения горелки и количество ее проходов), прогнозируется основной радиальный профиль показателя преломления (ППП) заготовки и при заданной оптимальной конструкции анизотропных световодов рассчитывается конструкция заготовок АОВС.

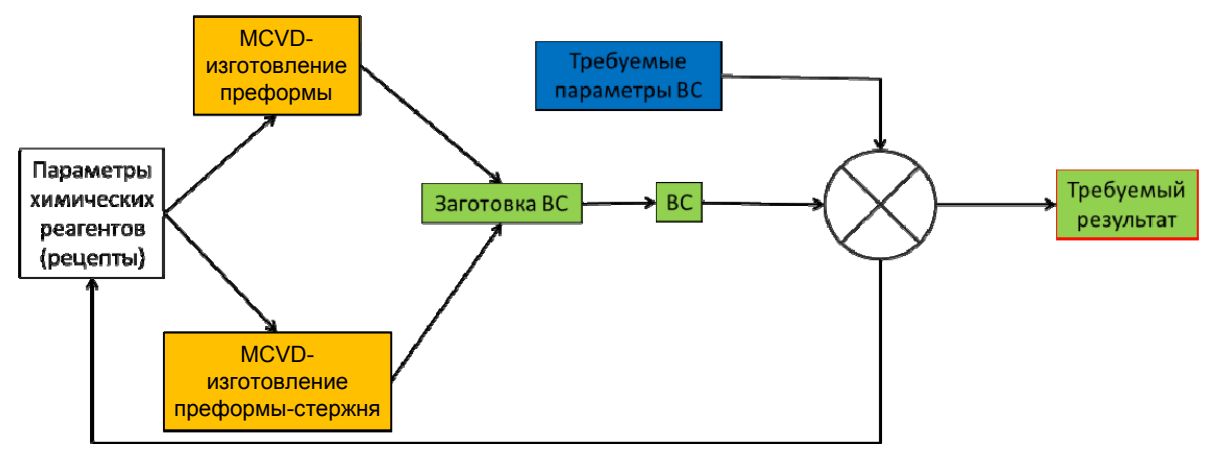

Рис. Общая схема процесса моделирования

Для получения прогнозируемого ППП решаются кинетические и термодинамические задачи процессов образования тонкодисперсных оксидов [1] и эффективности их осаждения, определяющейся толщиной стенки опорной трубки, скоростью перемещения горелки, длиной 
пути ее сканирования, условиями охлаждения трубки и малозависящей от скорости парогазового потока и диаметра трубки [2].

\section{2. Результаты и их обсуждение}

В ходе проведения математических расчетов и анализа полученных результатов составлена программа расчета целевой конструкции анизотропных световодов. Ее основные этапы:

1. Расчет технологического режима изготовления материнских преформ и преформ-стержней для получения требуемого ППП с учетом степени химического превращения галогенидов при взаимодействии с кислородом в оксиды и эффективностью осаждения оксидов. Сравнение расчетных данных и экспериментальных, определяемых с помощью рефрактографического способа в преформах, корректровка расчетных параметров.

2. Расчет параметров заготовки на основе технических требований к световодам.

2.1. Подбор коэффициента $K$, определяющего угол раскрытия $\alpha_{\text {ов }}$ оптимальной конструкции АОВС и расстояние от центра сердцевины до края канала $L$ в заготовке согласно работе [4] при заданных фактических параметрах заготовки: $D_{\text {кан }}-$ диаметр канала; $D_{\text {лег. ст }}-$ диаметр сердцевины нагружающего стержня; $z$ - зазор между каналом и стержнем:

$$
\begin{gathered}
K=\left(1+\sin \alpha_{\mathrm{oв}} / 2\right) /\left(1-\sin \alpha_{\mathrm{oB}} / 2\right), \\
L=\frac{D_{\text {заг }}}{2,66 K}-\frac{D_{\text {кан }}-D_{\text {лег. ст }}}{2} .
\end{gathered}
$$

2.2. Расчет угла раскрытия заготовки АОВС $\alpha_{\text {заг }}$ с учетом зазора $z$ и $\delta$ - толщины кварцевой оболочки нагружающего стержня:

$$
\alpha_{\text {заг }}=\left(\alpha \sin \left(\frac{D_{\text {лег. ст }}}{2} /\left(L+\delta+\frac{D_{\text {лег. ст }}}{2}+z\right)\right)\right) \text {. }
$$

2.3. Расчет геометрических параметров АОВС через параметры заготовки методом подобия.

2.4. Сравнение расчетных данных и экспериментальных, измеренных в АОВС; коррекция расчетных параметров.

3. По результатам п. 1 и 2.4 введение поправок в технологический режим. 


\section{Выводы}

В результате моделирования оптимизированы технологический процесс и конструкция АОВС, на основе которых волоконнооптические контуры гироскопа имеют $h$-параметр не более $5 \cdot 10^{-6} 1 / \mathrm{M}$, что на порядок меньше результатов до моделирования.

\section{Список литературы}

1. Исследование процессов легирования кварцевого стекла фтором методом модифицированного химического парофазного осаждения / А.Г. Андреев, В.С. Ермаков, И.И. Крюков, М.К. Цибиногина, К.В. Дукельский, М.А. Ероньян, Г.Т. Петровский, М.М. Серков // Физика и химия стекла. -2006 . - Т. 32, № 1. - С. 49-55.

2. Walker K.L., Geyling F.T., Nagel S.R. Thermoforetic deposition of small particles in the modified chemical vapor deposition (MCVD) process // J. Am. Ceram. Soc. - 1980. - Vol. 63, № 9-10. - P. 552-558.

3. Small form-factor Panda type HiBi fiber for sensing applications / M. Alam, D. Guertin, J. Farroni, J. Abramczyk, N. Jacobson, K. Tankala. -2003.

4. Способ получения одномодового волоконного световода: пат. № 2164698 Рос. Федерация / Курбатова А.М. - 2001.

\section{References}

1. Andreev A.G., Ermakov V.S., Kryukov I.I., Cibinogina M.K., Dukel'skij K.V., Eron'yan M.A., Petrovskij G.T., Serkov M.M. Issledovanie processov legirovaniya kvarcevogo stekla ftorom metodom modificirovannogo himicheskogo parofaznogo osazhdeniya. Fizika i himiya stekla, 2006, vol. 32 , no. 1, pp. 49-55.

2. Walker K.L., Geyling F.T., Nagel S.R. Thermoforetic deposition of small particles in the modified chemical vapor deposition (MCVD) process. J. Am. Ceram. Soc., 1980, vol. 63, no. 9-10, p. 552-558.

3. Alam M., Guertin D., Farroni J., Abramczyk J., Jacobson N., Tankala K. Small form-factor PANDA type HiBi fiber for sensing applications, 2003

4. Kurbatov A.M. Sposob polucheniya odnomodovogo volokonnogo svetovoda. Patent no. 2164698, 2001.

Получено 28.09.2017 